\title{
Learning Behaviours of Adolescents in Senior High Schools: Exploring the Impact of Authoritative and Authoritarian Parenting Styles as Determinants
}

\author{
Ebenezer Boakye (Mphil Arts Education) \\ Department of Arts Education, University of Cape Coast, Ghana
}

\begin{abstract}
The significant roles of parents in the success of their children, including their leaning behaviour that determines their performance is undoubtedly paramount. However, those various roles of parents may largely depend on the style(s) they adopt in their parental endeavours. The purpose of study was to examine the impact of parenting style on the learning behaviour of adolescents in the Senior High School in the Kumasi Metropolis in Ghana. To accomplish this, a descriptive survey research design procedure using a quantitative approach was employed. A sample size of 317 respondents was used for the study. Questionnaire was used to obtain data from the respondents. The data was analysed using inferential statistics (Pearson Product Moment Correlation). The study revealed that generally, the learning behaviour of adolescents in the Senior High Schools in the Kumasi Metropolis was greatly influenced by the type of parenting style the parents adopt. Conclusions and Recommendations are made in this work.
\end{abstract}

Keywords: Parenting, Authoritarian, Authoritative, Parents, Adolescent.

DOI: $10.7176 / \mathrm{JEP} / 12-07-01$

Publication date:March $31^{\text {st }} 2021$

\subsection{Introduction}

Parents play pivotal role in the development of their children. They are the immediate stakeholders in education of their children and the nature of parenting and relationship between themselves and their children have the capacity to impact their cognition and learning abilities at the early stages of the child's life (Nel and Van der Westhuizen, 2015:14). They should utilize positive parenting techniques for training their children. Future generation is the asset of a nation. Parenting styles and techniques have consistently been shown to relate to various outcomes among children such as psychological, emotional, and social and personality development problems (aggression), as well as cognitive development problems which may affect their learning behaviour and consequently their academic performance (Baumrind, 1991, Querido, Warner \& Eyberg, 2002; Turner, Chandler \& Heffer, 2009).

The type of parenting style adopted, whether same or dissimilar by parents, and consistency or inconsistencies in the enforcement of the dimensions of parenting impacts on the developmental outcomes of children and personality traits in life. Authoritarian parenting styles have generally been found to lead to children who are obedient and proficient, but rank lower in happiness, social competence, and self-esteem. Authoritative parenting styles tend to result in children who are happy, capable, and successful (Maccoby, 2015). In Ghana, until recently, most studies focused on community participation in school activities which found involving communities in schools as a worthwhile activity with beneficial effects in improving the infrastructure base of the schools and making resources available for educational success of the students (Addae-Boahene \& Akorful, 2000; Boardman \& Evans, 2000; Nkansah \& Chapman, 2006; Nyarko, 2011).

That is, these studies found community participation in schools as vital and stressed on the need for families, which make up the communities, to be involved in the academic pursuits of their wards as this helps to improve the academic success of their wards. However, the few studies on parenting styles and academic performance of students in Ghana found a relationship between the two variables and also found good performance to be associated with authoritative parenting style among students within the two distinct areas they conducted their studies (Addai, 2010; Nyarko, 2011). The researcher, hence, anticipated that parenting styles by parents characterised by different disciplinary strategies, communication styles, warmth and nurturance and expectations of maturity and control, to relate to and yield different academic achievements among students. The study also, anticipated high or good performance to be associated with authoritative style of parenting. Education has over the years been regarded as key to entire individual's development (Ali, McWhirter \& Chronister, 2005). Throughout one's life, it is education that remains central to shaping the goals and ideals of an individual, pace of coping with daily challenges and integral development. Society's development is also determined by the standards of education that people undergo. Hence aspects that determine an individual's academic achievement remain vital to any member of the society that values development. Though academic achievement is vital at every stage of personal growth it is regarded as crucial at adolescent stage; as this stage determines one's success or failure in life in what is described as identity crisis (Boon, 2007). Other scholars have also explored family 
factors such as parenting involvement and parenting styles to have influence on goal orientations as a kind of individual variable (Pintrich and Schunk, 2000). Again, there has also been evidence parading the influence of parental involvement on students' learning (Epstein, 1989).

Academic success relates to having high academic achievement in childhood (Kang, \& Moore 2011). Although there are likely many factors that influence academic success such as peer relationships, school environments, parenting styles may be especially an important influence on academic success. Moreover, in different cultures for example different countries and environments, there may be some diversity in children's academic achievement because of parenting style differences between countries (Kang \& Moore, 2011). Thus, parenting styles in different cultures may differentially impact children's academic achievement (Nyarko, 2011). The government of Ghana has been employing much energy through and channelling financial resources in the expansion of educational institutions and building their capacities to increase the rate of enrolment and to produce well trained and qualified citizens who can be partners in national development. In Ghana, however, few studies on parenting styles and academic performance have been conducted and these studies also found good performance to be associated with authoritative parenting style among students within the two distinct areas they conducted their studies (Addai, 2010; Nyarko, 2011; Ofosu-Asiamah, 2013).

\subsection{Statement of the Problem}

It is believed that students learning behaviours or study patterns have strong link with how their parents train them. Kumasi Metropolis has one of the most populated children and adolescents in the Ashanti Region (Ghana Statistical Service, 2010). However, these adolescent students in Senior High Schools in these areas do not place in the first hundred schools in the WASSCE rankings for at least the past 5 years. Researchers (Acheampong, 2005; Amedahe \& Gyimah, 2009; Ankomah, 2010, Etsey 2004, Ghartey \& Fletcher, 2011; Oduro, 2001) have indicated a problem of low academic achievement among the students in Ghana. Performance is indicated through various aspects, which differ from institution to institution. Indicators of performance include motivation, study skills, communication skills, creativity, creative writing, grades; student's working skills, self-realization, self-reliance and attitude as well as parenting styles.

Again, the students achievement have been found to have a strong link with their learning behaviour which is also found to be have strong link with the kind parenting style they are exposed to (Pintrich and Schunk, 2000; Gonzalez et al., 2002; Chan \& Cha 2005). This study therefore seeks find out if parenting styles (authoritative and authoritarian parenting styles affect the learning behaviour of adolescents. The focus is on these two parenting styles have been found to be very effective styles that seriously effect change in the behavioural patterns of adolescents.

\subsection{Research Questions}

1. What is the relationship between authoritative parenting style and learning behaviours of students in the senior high schools in the Kumasi Metropolis?

2. What is the relationship between authoritarian parenting style and learning behaviours of students in the senior high schools in the Kumasi Metropolis?

\subsection{Significance of the Study}

First, it is crucial for the students themselves and for their teachers to consider the connection between perceived parenting styles and learning behaviours, since the learning behaviours of students will impact both their learning policies as well as their teaching strategies. This awareness further makes us realize how the aspirations of potential primary students are tied to parenthood. Again, the significance of this study is to find out how the various parenting styles affect the learning behaviour of students in senior high and consequently their academic performance schools in the Kumasi Metropolis in the Ashanti region of Ghana. Understanding the impact of parenting styles on the learning behaviour of children and its effect on academic performance of students in senior high schools in the Kumasi Metropolis will enable Ministry of Education, Ghana Education Service and school administrators as well as policy makers to develop strategies and techniques for interventions to maximize student's academic success in secondary education institutions, in general. The findings of this study would help parents understand the important role they must play in the education of their children in order to ensure success. It will also help them to know which parenting style is more appropriate and how their involvement by means of their responsiveness and demandingness could go to ensure success for their children.

\subsection{Literature Review}

\subsection{Theoretical Groundings (Baumrind Theory)}

Baumrind developed the theory that there were four main types of parenting styles and that differences in parenting styles accounted for the way children functioned socially, emotionally, and cognitively. Baumrind suggested that there were four dimensions of parent-child interactions: parental control, maturity demands, 
clarity of communication and nurturance. She pointed out that parental control is related to issues such as enforcing rules; Maturity demand is the parental expectation that children perform up to their potential; Clarity of communication reflects the parents' willingness to communicate with their children, solicit their opinions and use reasoning to obtain the desired behaviour and Nurturance is related to parental expressions of warmth and approval, and protection of children's physical and emotional well-being (Baumrind, 2012).

Using these four dimensions, Baumrind identified four parenting styles: authoritative, authoritarian, permissive-indulgent and permissive-uninvolved. She pointed out that the authoritative style is considered as the ideal parenting style and seems to produce children with high levels of self-reliance and self-esteem, who are socially responsible, independent and achievement oriented. Authoritative parents set clear expectations and have high standards. They monitor their children's behaviour, use discipline based on reasoning and encourage their children to make decisions and learn from their mistakes. They are also warm and nurturing, treating their children with kindness, respect, and affection. On the other hand, authoritarian parent tends to set rigid rules, demand obedience, and use strategies such as the withdrawal of love or approval to force a child to conform. These parents are more likely to use physical punishment or verbal insults to elicit the desired behaviour. They lack the warmth of the authoritative parent and may seem aloof to their children. Children with authoritarian parents may be well-behaved, but they are also likely to be moody and anxious; they tend to be followers rather than leader.

\subsection{Conceptual Review}

\subsubsection{Child Outcomes from Authoritarian Parenting Style}

The lack of balance in the four dimensions of parenting and the extensive stress on disciplinary strategies and high expectations of maturity and control leads to the development of different negative outcomes in the child. Children from such homes are known to develop personality traits such as: being rebellious; fighting or quarrelling; being extremely submissive; indecisive; lacking spontaneity as they always want to be told what to do. Psychologically the following outcomes are usually the case. That is, they: exhibit anxious and withdrawn behaviours; lack self-reliance; have an external locus of control; have low self-esteem and timid; lack intrinsic motivation to achieve anything in life. As far as their social outcomes are concerned, they: are anti-social in nature; lack social competence to deal with problems and are passively optimistic; have improper social attitudes; have weak communication skills; have inappropriate social behaviour such as drug use. Finally, emotionally they are: known to be unhappy; are fearful; insecure and have trust issues; not known to show love to others; and are easily angered.

Some parents seeing the vital role of a mastery of goal orientation will then collaborate with the school to promote this orientation in their children, while other parents may believe that a mastery of goal orientation will not help to prepare their children for competition in the 'real world' (Pintrich and Schunk, 2000). Parental influence on their child's adoption of mastery and performance goals may be affected by the parenting styles perceived by their children (Chan and Chan, 2005). Parents may influence indirectly their children's adoption of mastery learning goal.

Chan and Chan (2012) aver that students' perceived parenting styles and goal orientations is important both for the students themselves and for their lecturers, because the students' goal orientations may affect both their learning strategies and their teaching strategies. This in the end affect their performance.

\subsubsection{Authoritative Parenting Style}

This style of parenting is high in all four dimensions of family functioning, that is disciplinary strategies, warmth and nurturance, communication styles, and expectations of maturity and control. It is characterized by an optimum balance of responsiveness and demandingness. As noted by Maccoby (2015), authoritative parents know and understand children's independence, encourage verbal communication, allow children to participate in decision making of the family, and want the children progressively undertake more responsibility for reacting to the needs of other people in the family within their abilities. This type of parenting style consists of a constellation of parental characteristics of high standards, such as high emotional attachment and support to children, encouragement of a two-way communication between parents and children, and consistent implementation of the rules established by parents (Baumrind, 1991; Abesha, 2012). They consistently monitor conduct and use non-punitive method or discipline when rules are violated. Socially responsible mature behaviour is expected and reinforced. Authoritative parents are also warm and supportive. They encourage and validate the child's individual point of view and recognize the rights of both parents and children". Authoritative parenting style therefore creates warm, loving, and mutual understanding in the family and foster stable children's behaviour and personality (Glasgow, Dornbusch, Troyer, Steinberg, \& Ritter, 1997; Talib, 2011; Hong \& Hong, 2012).

Baumrind (1991) avers that, "unlike any other pattern, authoritative upbringing. consistently generated competence and deterred problem behaviour" (p.91). Authoritative parenting has been found to be an essential factor in an adolescent's life in comparison with the other parenting styles. It has been seen as the most effective 
in enhancing personal and social responsibilities in adolescents, without constraining their newly formed autonomy and individuality (Glasgow et al., 1997; Hong \& Hong, 2012).

This democratic approach acknowledges the child's need for both discipline and individuality (Tiller, Garrison, Block, Cramer \& Tiller, 2003), promoting an open relationship where problems can be discussed and resolved together as a team. Authoritative parents often hold high expectations for their children and consistently encourage them along the way. Steinberg, Lamborn, Dornbusch and Darling (2015) suggested that authoritativeness holds the central trio in good parenting - warmth, control, and democracy, which explains why it is often deemed as the most successful parenting style for student achievement.

\subsubsection{Child Outcomes from Authoritative Parenting Style}

The authoritative parenting style, various studies have found to be the most beneficial for children and adolescents because it is positively correlated to numerous positive outcomes (Baumrind, 1991; Abesha, 2012). These positive developmental outcomes could be attributed to the balance in the four dimensions of parenting. These outcomes are manifested in many ways in the child. With respect to the child's personality traits, children from authoritative homes who experience an optimal balance in the four dimensions of parenting turn out to be: decisive and high achievers; self-disciplined; respectful and polite; assertive and independent; self-confident and creative. Psychologically, they are known to be: self-reliant; good developers of high self-esteem and actively optimistic; well-developed cognitively; intrinsically motivated; and have an internal locus of control. Socially, they are regarded as: socially competent in dealing with social problems; having friendly relations with others and cooperating well with others; playing social roles effectively and efficiently; having good communication skills; being capable of adjusting themselves properly in society. Finally, these children are known for the following emotional outcomes. They are: cheerful; emotionally stable; compassionate and empathetic; known to develop a sense of security and have no trust issues; known for their ability to express love towards others.

\subsection{Empirical Review on Authoritarian Parenting Style, Learning Behaviour and Academic Performance}

In this authoritarian style of parenting, children are expected to follow strict rules established by the parents. Failure to follow such rules usually results in punishment. Authoritarian parents fail to explain the reasoning behind these rules. If asked to explain, the parent might simply reply, "Because I said so." Talib (2011) described parents with this type of parenting style as highly demanding an unresponsive. These parents attempt to mould and control the behaviour and attitudes of their children according to a set of standards. They tend to emphasize obedience, respect for authority, and order. Authoritarian parents also discourage verbal give-andtake with children, expecting rules to be followed without further explanation. Again, Abesha (2012) also observed that authoritarian style of parenting is marked by parental behaviours that are highly restrictive and very demanding. It is high in control and maturity demands, but low in nurturance and bi-directional communication between parents and children. Authoritarian parents constrain their children's independence, and they want their children to follow strict parental rules and orders without any question by threatening severe punishment if children violate these rules and orders. These parents have high demands but are not responsive to their children. In addition, these parents are usually obedience and status oriented, and they always expect their orders to be obeyed without explanation (Karavalis, 2003).

Parents in the restrictive pattern of parenting are identified as authoritarian. Parents in this type attempt to sharpen, control, and evaluate the behaviour and attitude of their children which is usually formulated by a higher secular authority (Baumrind, 1999). These parents are high on demandingness and low on responsiveness (Maccoby \& Martin, 2003). Additionally, children and adolescents with authoritarian parents were reported as having low self-esteem and spontaneity, as well as withdrawal, antisocial, and delinquent behaviours (Roberts \& Fraleigh, 2016). Parents in this pattern value obedience as a virtue and are punitive and forceful (Baumrind, 1999).

A study conducted by Roberts and Fraleigh (2016) indicated that authoritative parenting positively related to grades; conversely, both authoritarian and authoritative parenting negatively related to grades. However, authoritarian parenting is inclined to have a stronger relationship with grades rather than the other two parenting styles. This is because authoritarian parenting tends to be characterized by power. The findings of a study conducted in Ethiopia documented that an authoritarian parenting style was the most commonly practiced parenting style since socio-political system adhered to authoritarianism in every realm of human endeavours. On the other hand, a likely reason for the findings of the studies in the last two decades which reported that an authoritative parenting style was the most predominantly employed parenting style could be, as noted by numerous researchers (Roberts \& Fraleigh, 2016).

Ethiopian parents for example attach very high values to their children in the hope that they will provide social, economic, and psychological support for their parents especially when they become older, and to ensure the continuity of family lineage. Another possible explanation could be that the rapid socio-political changes that have been induced in the country in the drive for modernization and globalization may have resulted in some cultural changes including childrearing practices. This is why some investigators affirmed that a change in the 
socio- political system is accompanied by cultural changes (Mapes, 2008). For these reasons, parents may employ more accepting, firm, and democratic child rearing practices which is authoritative parenting style.

\subsubsection{Authoritative Parenting Style, Learning Behaviour and Academic Performance}

The parents with an authoritative parenting style usually establish rules and guidelines that their children are expected to follow. However, this parenting style is much more democratic, and the parents are more responsive to their children and willing to listen to questions. When children fail to meet the expectations, these parents are more nurturing and forgiving rather than punishing. Baumrind (1991) suggests that these parents usually monitor and impart clear standards for their children's conduct; they are assertive, but not intrusive and restrictive. Their disciplinary methods are always supportive, rather than punitive since they want their children to be assertive as well as socially responsible, and self-regulated as well as cooperative. A study by Gonzalez et al. (2002) on North American high-school students revealed that Mastery or learning goals were positively and significantly related to perceptions of authoritative parenting by both parents, and there were positive and significant correlations between high-school students' performance orientations and perceptions of maternal and paternal authoritarianism.

Authoritative parents promote the creation of individuality for their children and focus on interpretations of laws instead of rigid discipline. Children raised by authoritative parents rely more on decision-making authority and are less susceptible to exploratory and demanding conduct. Children with allowed parents typically lack autonomy, little anger tolerance and little chance of persisting in learning activities. Children growing up under authentic parentage are more self-reliant and academically inclined to take explorative conduct. These results indicate potential associations between parenting and children's motivative objectives (Chan \& Chan, 2005).

Authoritative parents have high demandingness and high or medium responsiveness (Roberts \& Fraleigh, 2016). Moreover, authoritative parents reasonably attempt to direct their children's activities and use more warm control, positivity during communication, feelings-oriented reasoning as well as induction, and more responsiveness to children's questions (Mize \& Pettit, 1997). Interestingly, adolescents with authoritative parents reported higher grades in school performance than adolescents with neglectful parents, and demonstrated stronger school orientation, school engagement, and bonding with teachers than adolescents with neglectful parents (Steinberg, Eisengart, \& Cauffman, 2006). Demanding parents are medium responsive and high demanding (Baumrind, 1999). However, traditional parents exhibited a different structural role between mothers and fathers. For example, mothers are highly responsive however, relatively understanding. In contrast, fathers are highly demanding, but quite coercive and non-responsive.

Advantages of authoritative parenting may differ depending on the particular ethnic groups. For instance, European American, African American, Asian American, and Hispanic American were compared by Steinberg et al. (2015) in order to look at the influence between parenting styles and academic achievement for adolescents. The findings revealed that European American, African American, and Hispanic American adolescents' higher school achievement was significantly predicted by authoritative parenting, but this was not the case for Asian American adolescents. Also, Steinberg et al. (2015) found that the parents of European American adolescents were most likely to use authoritative parenting. In contrast, Asian American adolescents' parents were the least likely to use authoritative parenting.

\subsection{Methodology}

The study used cross-sectional descriptive and correlation studies with a quantitative approach. A Crosssectional design is one that justifies the process of collecting data on specific social phenomena at a single point in time to verify the relationships among stated variables (Bryman, 2012). It is desirable to institute this design because the researcher wants to capture the narratives of parenting from sections of parents. Purposive sampling was used to select the location and the participants. Purposive sampling was used to select in the Kumasi Metropolis and all the five senior high schools in the Metropolis. Proportional sampling technique was used to select the sample size of form three students based on the population in each senior high school. To simplify the process of determining the sample size for a finite population, researchers recommend Krejcie and Morgan table since it is adequate for the descriptive study. Therefore, using the Krejcie and Morgan table the sample size of the total population of 1717 was about 317 students. The structured questionnaire was administered to the students. The data were analysed and discussed quantitatively using inferential statistics (Pearson product moment correlation, ppmc).

\subsection{Results and Discussion}

RQ1: What is the relationship between authoritative parenting style and learning behaviour of students in the senior high schools in the Kumasi Metropolis?

To determine whether there is relationship between authoritative parenting styles and learning behaviour of students in the senior high schools in the Kumasi Metropolis, Pearson Product moment correlation was deemed appropriate. The result is presented in table 1 
Table 1: Relationship between authoritative parenting style and learning behaviour of senior high school students

\begin{tabular}{lccc}
\hline & & Authoritative & Learning Behaviour \\
\hline Authoritative & Pearson Correlation & 1 & $.989^{*}$ \\
& Sig. (2-tailed) & & .000 \\
N & 317 & 317 \\
Learning & Pearson Correlation & $.989^{*}$ & 1 \\
Behaviour & Sig. (2-tailed) & .000 & 317 \\
& $\mathrm{~N}$ & 317 &
\end{tabular}

From Table 1, the results from the analysis revealed that authoritative parenting styles correlate high with learning behaviour and the results show a statistically significant relationship between the variables. This was evident after the two variables produced the result of $\mathrm{r}(317)=.989, \mathrm{p}=.000$ (2-tailed) which is less than $\mathrm{p}$ value of .05. This, therefore, suggests authoritative parenting style influences students' learning behaviour.

The current finding agrees with the work of Steinberg et al. (2015) who postulate that advantages of authoritative parenting may differ depending on the particular ethnic groups. For instance, European American, African American, Asian American, and Hispanic American were compared by Steinberg et al. (2015), in order to look at the influence between parenting styles and learning behaviour for adolescents. The findings revealed that European American, African American, and Hispanic American adolescents' higher school achievement due to their learning behaviour being influenced by the parenting styles that their parents adopt, this was significantly predicted by authoritative parenting, but this was not the case for Asian American adolescents.

RQ2: What is the relationship between authoritarian parenting style and learning behaviour of students in the senior high schools in the Kumasi Metropolis?

To further examine whether there is relationship between authoritarian parenting style and academic performance of students in the senior high schools in the Kumasi Metropolis, again the Pearson Product moment correlation was deemed appropriate. The result is presented in Table 2.

Table 2: Relationship between authoritarian parenting styles and learning behaviour of senior high school students.

\begin{tabular}{cccc}
\hline & & Authoritarian & Learning Behaviour \\
\hline Authoritarian & Pearson Correlation & 1 & $.931^{*}$ \\
& Sig. (2-tailed) & & .000 \\
Learning & $\mathrm{N}$ & 317 & 317 \\
Behaviour & Pearson Correlation & $.931^{*}$ & 1 \\
& Sig. (2-tailed) & .000 & 317 \\
\hline
\end{tabular}

**. $P<0.05$ level (2-tailed), $N=317$

From Table 2, the results from the analysis revealed that authoritarian parenting style correlates high with learning behaviour and the results demonstrate a statistically significant relationship between the variables. This was evident after the two variables produced the result of $r=.931, n=317, p=.000,2$-tailed) which is less than $p$ value of .05. This, therefore, suggests that authoritarian parenting style influences students' learning behaviour. The findings from the study lend support to the work of Talib et al. (2011) who described parents with authoritarian type of parenting style as highly demanding and unresponsive and this is likely to influence students' academic achievement. Similarly, Abesha (2012) also observed that authoritarian style of parenting is marked by parental behaviours that are highly restrictive and very demanding and this influences students' behaviour in all aspect. In addition, these parents are usually obedient and status oriented, and they always expect their orders to be obeyed without explanation (Karavalis, 2003). Again, a study conducted by Roberts, and Fraleigh (1997) indicated that authoritative parenting positively related to grades; conversely, both authoritarian and authoritative parenting negatively related to grades. However, authoritarian parenting is inclined to have a stronger relationship with good grades rather than the other two parenting styles. This style of parenting has been related to an extrinsic motivational orientation, a construct which is related to the performance goal orientation, (Ginsburg \& Bronstein, 1993). Authoritarian parenting is likely to be correlated with student's who have less capacity to experience pleasure in work and are more dependent upon others (Steinberg, Elmen, \& Mounts, 1989; Steinberg, Lamborn, Darling, Mounts, \& Dornbusch, 1994; Lamborn, Mounts, Steinberg, \& Dornbusch, 1991). Parental authoritarianism has been correlated with dependence on authority figures and tendency to withdraw from challenging academic situations (Baumrind, 1967, Baumrind \& Black, 1967; Maccoby \& Martin, 1983).

\subsection{Conclusions}

Based on the findings of the study, it can be concluded that learning behaviour of adolescents in the senior high 
schools in the Kumasi Metropolis is greatly influenced by the type of parenting style the parents adopt. However, among the parenting styles, authoritative parenting seems to have more influence on the learning behaviours. However, the findings from study suggest that differences in learning behaviours of students in the study area were because of the variations in parenting styles used by parents. Overall, authoritarian parenting style was found to have the most significant effect on students' learning behaviour and students from authoritarian homes were found to be very effective in their learning behaviours than the others from other parenting homes.

\subsection{Recommendations}

It is recommended that the Municipal Assembly, the Ghana Education Service Head teachers and teaching staff in the various senior high schools in the Kumasi Metropolis should generate a policy geared towards the creation of awareness of parenting styles and their dimensions of parenting. The awareness of the impact of the various styles of parenting used by parents on their adolescent children must be made known to them. Knowledge of the negative or positive impact of the parenting styles and their dimensions on children's development will help parents to adopt the right parenting style and its dimensions.

Secondly, I recommend that the community and all the structures within it including schools, community heads, churches and media must help in ensuring that parents are more responsible towards their children and also provide the needed support necessary for students to achieve a holistic growth. Parent-Teacher Associations, Civil Society Organizations should derive policies that would ensure parents are more involved in the education of their children. Parents would be compelled to put in much effort in order to meet their children's needs if the society places much emphasis on education of the adolescents. Parents who are found insensitive to the necessities of their children should be sanctioned if possible.

\section{References}

Abesha, A. G. (2012). Effects of parenting styles, academic self-efficacy, and achievement motivation on the academic achievement of university students in Ethiopia. Edith Cowan University, Perth, Western Australia

Addae-Boahene, K., \& Akorful, K. (2000). Improving quality education through community participation: SMC/PTA training guide. Quality improvements in partnership schools (QUIPS), Accra, Ghana.

Addai, F. (2010). The effect of parenting style and parental involvement on students academic performance, University of Education, Winneba.

Baumrind, D. (2012). The influence of parenting style on adolescent competence and substance use. Journal of Early Adolescence, 11(1), 56-95.

Baumrind, D. (1991). The influence of parenting style on adolescent competence and substance use. Journal of Early Adolescence, 11, 56-95

Baumrind, D. (1971). Current patterns of parental authority. Developmental Psychology Monographs, 4, 1-103.

Baumrind, D. (1967). Child-care practices anteceding three patterns of preschool behaviour. Genetic Psychology Monographs, 75, 43-88.

Boardman, G., \& Evans, L. R. (2000). Community support for education: Local change leaders. Community school alliance, Accra, Ghana.

Boon, J.H. (2007). Low and high achieving Australian Secondary school students: Their parenting, motivations, and academic achievement. Australian Psychological Society, Vol 42, 212-225.

Bronfenbrenner, U. (1979). The ecology of human development: Experiments nature and design. Cambridge, MA: Harvard University Press.

Bronfenbrenner, U. (1977). Toward an experimental ecology of human development. American Psychologist, 513-531.

Bryman, A. (2012) Social research methods ( $4^{\text {th }}$ ed.). Oxford University Press.

Cherry, K. (2012). The four parenting.About.com.www.psychology.about.com/od/developmentalpsychology/a/parenting-style.htm.

Darling, N., \& Steinberg, L. (1993). Parenting style as context: An integrative model. Psychological Bulletin, 113(3), 487-496.

Roberts, D., \& Fraleigh, M. (2016). The relation of parenting style to adolescent school performance. Child Development, 58, 1244-1257.

Hong, E. (2012). Impacts of Parenting on Children's Schooling. Journal of Student Engagement: Education Matters, 2 (1), 36-41.

Kang, Y. \& Moore, J. (2011). Parenting style and adolescents' school performance in mainland China'. USChina Education Review, B (1), 133-138.

Lamborn, S. D., Mounts, N. S., Steinberg, L., \& Darnbush, S. M. (1991). Patterns of competence and adjustment among adolescents from authoritative, authoritarian, indulgent, and neglectful families. Child Development, $62,1049-1065$.

Mugenda, O. \& Mugenda, A. (2003). Research methods qualitative and quantitative Research. Act Press; Kenya. 
Nairobi.

Muller, C. (1993). Parental involvement and academic achievement: An analysis of family resources available to the child. In Schneider, B., and Coleman, J. S. (eds.), Parents, Their Children, and Schools, Westview, Boulder, CO, 73-113.

Muthivhi, A.E., (2010). Piaget, Vygotsky, and the cultural development of the notions of possibility and necessity: An experimental study among rural South African learners. South Afr. J. Psychol. 40, 139-148.

Nel, M. \& Van derWesthuizen, Z., (2015). Skokkend positief, Bybelmeia, Kaapstad.

Nkansah, G. A., \& Chapman, D. W. (2006). Sustaining community participation: What remains after the money ends? International Review of Education, 52(6), 509-532.

Nyarko, K. (2011). The influence of authoritative parenting style on adolescents' academic achievement, 278282.

Pong, S., Hao, L., \& Gardner, E. (2005). The roles of parenting styles and social capital in the school performance of immigrant Asian and Hispanic adolescents. Social Science Quarterly, 86, 928-950.

Querido, J.G., Warner, T.D., \& Eyberg, S.M. (2002). Parenting styles and child behavior In African American families of preschool children. Journal of Clinical Child \& Adolescent Psychology, 3(2), 272-277.

Steinberg, L., Lamborn, S.D., Darling, N., Mounts, N.S., \& Dornbusch, S.M. (1994). Over-time changes in adjustment and competence among adolescents from authoritative, authoritarian, indulgent, and neglectful families. Child Development, 65, 754-770.

Steinberg, L., Lamborn, S.D., Dornbusch, S.M., \& arling, N. (1992). Impact of parenting practices on adolescent achievement: Authoritative parenting, school involvement, and encouragement to succeed. Child Development, 63, 1266-1281.

Steinberg, L., Dornbusch, S. M., \& Brown, B. B. (2015). Ethnic differences in adolescent achievement: An ecological perspective. American Psychologist, 47(6), 723729.

Steinberg, L., Lamborn, S. D., Dornbusch, S. M., \& Darling, N. (2015). Impact of parenting practices on Adolescents achievement: Authoritative parenting, school involvement and encouragement to succeed. Child Development, 63, 1266-1281.

Turner, E.A., Chandler, M. \& Heffer, R.W. (2009). The influence of parenting styles, achievement motivation, and self-efficacy on academic performance of college students. Journal of College Student Development, Vol. 50(3), May/June, pp.337-346. 